\title{
Hyaluronic acid hydrogels formed in situ by transglutaminase-catalyzed reaction
}
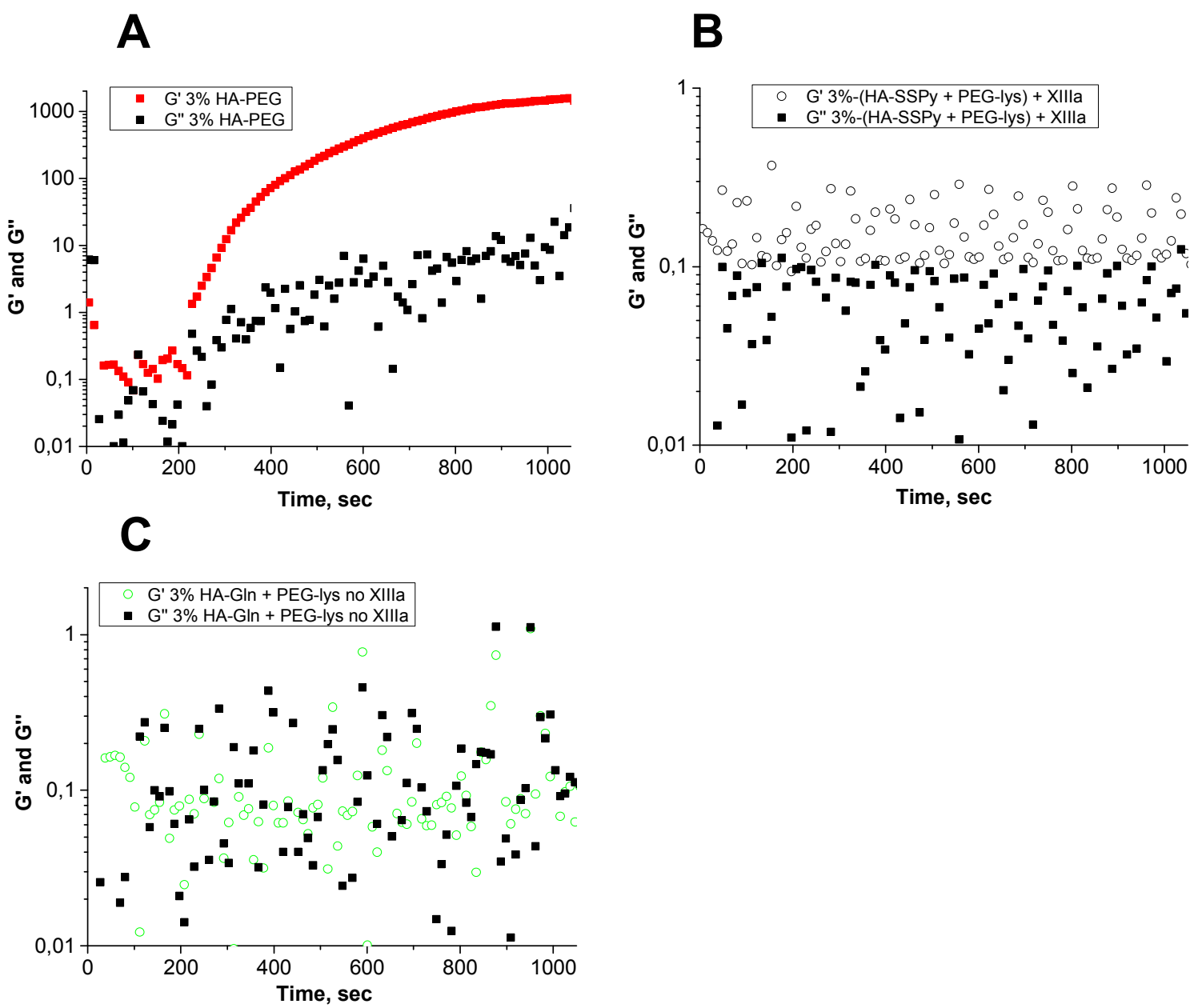

Figure S1. Small-strain oscillatory shear rheometry to determine gelation kinetics in situ. (a) Evolution of storage $\left(\mathrm{G}^{\prime}\right)$ and loss $\left(\mathrm{G}^{\prime \prime}\right)$ moduli during the first 1000 seconds after mixing of HAGln and PEG-Lys $([G \ln ] /[L y s]=1)$ at $3 \%$ concentration. For comparison, HA-Gln was substituted with the same amount of HA-SSPy (b), as well as factor XIIIa was omitted from the mixture of HAGln and PEG-Lys (c). $\mathrm{G}^{\prime}$ and $\mathrm{G}^{\prime \prime}$ were measured at $0.2 \mathrm{~Hz}$. 